\title{
Effect of Selected Exercise Program on Quality of Life in Stroke Patients
}

\author{
MAI M. GAMAL, M.Sc. ${ }^{1}$; GEHAN M. AHMED, Ph.D. ${ }^{2}$; AMIRA M. ABDEL RAHMAN, M.D. ${ }^{3}$; \\ RANIA M. TAWFIK, Ph.D. ${ }^{2}$ and MAHMOUD Y. ELZANATY, Ph.D. ${ }^{4}$ \\ The Department of Physical Therapy for Neuromuscular Disorders \& its Surgery, Faculty of Physical Therapy, \\ Badr \& Cairo Universities, Physiology, Faculty of Medicine, Badr University ${ }^{3}$ and Physical Therapy for Neuromuscular \\ Disorders and its Surgery, Faculty of Physical Therapy, Cairo University and Deraya University, Egypt ${ }^{4}$
}

\begin{abstract}
Background: Stroke is one of the leading causes of death and long-term disability worldwide.

Aim of Study: This study aimed to conduct the effect of selected exercise programe on quality of life in stroke patients.

Material and Methods: Ten male patients with stroke enrolled in this study. A selected physical therapy program was provided for the selected group (GS) including: Passive Range of motion exercises for tightening muscles, Facilitation for weak muscles through: PNF technique, quick stretching. The Outcome Measures: The Arabic version of a short form dimension test (SF-36) used to assess the QOL Items of the SF-36 were divided into eight different domains. The control group was evaluated before and after intervention with a QOL questionnaire (SF36).
\end{abstract}

Results: There was a revealed significant increase in physical functioning, energy/fatigue, emotional well-being, social functioning, pain and general health post treatment compared with that pretreatment. Also, there was no significant difference in role limitations due to physical health and role limitations due to emotional problem between pre and post treatment in the selected group.

Conclusion: Selected physical program, significantly improves quality of life in patients with stroke.

Key Words: Strokee-Exercise-Quality of life.

\section{Introduction}

STROKE is characterized as an acute neurologic deficiency that lasts more than 24 hours and is caused by a cerebrovascular etiology, according to the World Health Organization. Ischemic stroke (caused by vascular occlusion or stenosis) and hemorrhagic stroke (caused by a vascular rupture resulting in intra-parenchymal and/or subarachnoid

Correspondence to: Dr. Mai M. Gamal, The Department of Physical Therapy for Neuromuscular Disorders \& its Surgery, Faculty of Physical Therapy, Badr University hemorrhage) are the two types of stroke. Eightyseven percent of all stroke cases are ischemic, ten percent are hemorrhagic, and three percent are caused by subarachnoid hemorrhage [1]

Stroke is very common all over the world, and individuals who have had a stroke are more likely to need assistance with mobility, self-care, and household tasks. Consequently, as opposed to matched monitors, they are forty percent more likely to have activity limitations. As a result, developing and implementing strategies to avoid and treat post-stroke disabilities and complications, as well as promoting accessibility, is critical [2].

Physical activity (including exercise) has a variety of benefits and effects that are likely to address the top ten research priorities following stroke. Even in high-functioning stroke survivors, higher levels of physical activity are associated with improved balance, walking ability, and physical fitness; however, people are often sedentary after a stroke. The current evidence supports poststroke exercise in a group setting with other people [3].

Post-stroke rehabilitation interventions aim to improve physical limitations, restore health-related quality of life (HRQOL), and reduce depressive symptoms. It is critical to investigate outcomes that go beyond motor function because a growing body of literature shows that stroke survivors experience social isolation and difficulty reintegrating into the community [4]

\section{Aim of study:}

The study aimed to conduct the effect of selected exercise programe on quality of life in stroke patients. 


\section{Material and Methods}

\section{1-Design of the study:}

The study was a one-group pretest-posttest design study. A pretest observation of the dependent variables was made before implementation of the treatment to the selected group, the treatment was administered \& finally a posttest observation of dependent variables was carried out to assess the effect of treatment on the group.

\section{2- Patients:}

The patients were recruited from outpatient clinic of Faculty of Physical Therapy, Cairo University, Egypt. In period between October 2020 to March 2021. Participants were invited to join the study and signed the written consent form prior to participation. The patients were assigned into one study group (GS). The study was conducted on ten male hemi-paretic patients following a stroke in the domain of the carotid artery. The patients were diagnosed and referred to a neurologist. The selection of patients was based on careful history taking and neurological examination conducted by a neurological sheet. A computed tomography scan and/or MRI used to confirm the diagnosis.

The patients were chosen under the following criteria:

1- The Patient's age ranged from 50-65 years.

2- The duration of the illness was not less than six months and not more than two years.

3- The patient's blood pressure was examined for safety monitoring resting systolic blood pressure (SBP) $<150 \mathrm{~mm} \mathrm{Hg}$ and/or resting diastolic BP (DBP) $<90 \mathrm{~mm} \mathrm{Hg}$.

4- The muscle tone of the affected upper and lower limbs ranged from 1 to $1+$ according to the modified Ashworth scale.

5- Muscle power of the affected upper and lower limbs not less than grade three according to manual muscle test.

6- Motor recovery for both upper and lower limbs stage IV, V according to Brunnstrom motor recovery stages.

7- Body Mass Index normal weight (18.5-25) and overweight (25-30) kg/m 2 .

8- Patients with sufficient cognitive abilities that enable them to understand and follow instructions (Mini-Mental Scale >24).

\section{The Current study excluded patients who have:}

1- Neurological diseases that affect the quality of life other than stroke (e.g: Multiple sclerosis, Peripheral neuropathy, Parkinsonism ... etc.).
2- Musculoskeletal disorders such as severe arthritis and fracture.

3- Cardiovascular problems (unstable angina, recent myocardial infarction within the last three months, congestive heart failure, significant heart valve dysfunction) or pulmonary disorders.

4- All patients suffered from uncontrolled diabetes mellitus and uncontrolled hypertension.

5- They have a language or communication barrier that prevents the completion of questionnaires.

6- Visual, auditory problems.

A verbal explanation about the important justification and main points of achievement of the study was explained to every patient.

The procedures of the current study were divided into two main categories:

Measurement procedures:

a- Initial evaluation procedures (initial phase):

- Each patient was examined medically in order to exclude any abnormal medical problems which previously mentioned.

- Each patient's history was taken in previously prepared questionnaire to collect information about, name, age, BMI and determination about any functional, social, psychological problems.

- The purpose of evaluation procedures were explained in steps for each patient in each group.

\section{b- Technical measurements phases:}

The patients were assessed before and after the study using:

Stroke quality of life assessment scale. The Arabic version of a short form dimension test (SF36) used to assess the QQL, Items of the measure: Items of the SF-36 were divided into eight different domains. All groups were evaluated before and after intervention with a QOL questionnaire (SF36). Physical Functioning, Role Limitations due to Physical Health, Role Limitations due to Emotional Problems, Energy/Fatigue, Emotional well-being, Social Functioning, Bodily Pain, General Health. Each patient was allowed to be familiar with the scale before starting the recording. To start the evaluation process, The patients were seated in a comfortable relaxed position, The patients were asked to answer items referring to the activities past four weeks, Items within subscales were totaled to provide a summed score for each subscale or dimension.

Weight and height scale: Weight and height were measured for each patient in all groups before 
treatment to calculate the body mass index (BMI) according to the following equation:

$$
\mathrm{BMI}=\text { Weight }(\mathrm{Kg}) / \text { height }\left(\mathrm{m}^{2}\right) \text {. }
$$

Blood pressure monitoring by (Aneroid Sphygmomanometers): Aneroid sphygmomanometers were used to obtain a BP reading [5].

Pulse-oximetry for ( $\mathrm{SPO}_{2}$ ): Were commonly used in to noninvasively measure arterial oxyhemoglobin saturation (SpO2) and heart rate (HR) at baseline and with therapeutic interventions [6] Pulse oximeter important to help achieve an exercise intensity that within the prescribed target heart rate range.

Target heart rate: The minimum number of heartbeats in a given amount of time to reach the level of exertion necessary for cardiovascular fitness, specific to a person's age, gender, or physical fitness. Readings preferably were taken while the patient was seated comfortably in a chair. The patients were examined in a room with a comfortable temperature. For monitoring resting heart rate: Taking pulse from the radial artery then count pulses for one minute [7].

- Maximum Heart Rate Formula: HRmax (pred) $=206.9-(0.67 \times$ age $)[8]$.

- Calculate heart rate reserve (HRR) by subtracting resting heart rate from maximum heart rate. Multiply HRR by 0.64 (64\%). Add resting heart rate to this number, Multiply HRR by 0.76 $(76 \%)$. Add resting heart rate to this number.

\section{Therapeutic procedures:}

Therapeutic intervention for the study was started at the same time for all patients in the study, the session time was $50-60 \mathrm{~min}$ divided as the following:

\section{Selected group $(G S)$ :}

Patients received Warm up (simple stretching exercise for all muscle groups) for 3-5min: Seslected physical training for (40-45min) three times a week for eight weeks (24 sessions in total), patients were allowed to rest if necessary, Cool down (simple stretching exercise for all muscle groups)for (3-5min).

\section{Selected physical training program:}

- Passive Range of motion exercises for tightening muscles of upper and lower limbs.

- Facilitation for weak muscles through:
- Proprioceptive Neuromuscular Facilitation technique for affected upper and lower limbs. patients will be allowed to rest if necessary.

- Quick stretching for upper and lower limbs.

\section{Data analysis:}

Subjects' characteristics were summarized using mean and standard deviation for numerical data and using frequency for categorical data. Wilcoxon Signed Ranks Test was conducted for comparison between pre and post treatment median values of quality-of-life items. The level of significance for all statistical tests was set at $p<0.05$. All statistical analysis was conducted through the statistical package for social studies (SPSS) version 25 for windows (IBM SPSS, Chicago, IL, USA).

\section{Results}

\section{Subject characteristics:}

Ten male patients with stroke participated in this study. Table (1) showed the subject characteristics of the study group.

\section{Effect of treatment on quality of life:}

Within-group comparison revealed a significant increase in physical functioning, energy/fatigue, emotional well-being, social functioning, pain and general health post treatment compared with that pre-treatment $(p<0.05)$. However, there was no significant difference in role limitations due to physical health and role limitations due to emotional problem between pre and post treatment in the study group $(p>0.05)$. (Table 2$)$.

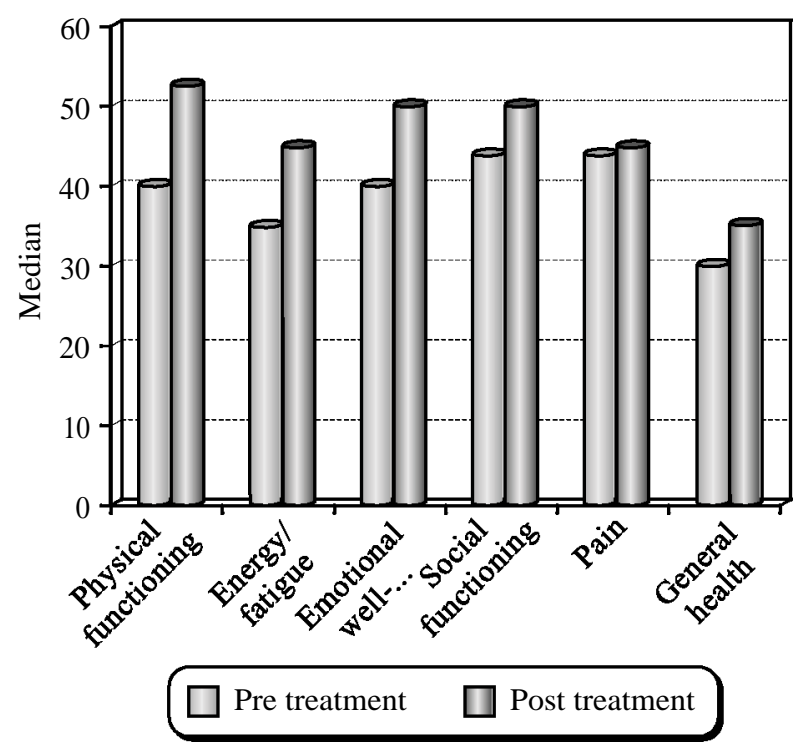

Fig. (1): Median values of physical functioning, role limitations due to physical health, role limitations due to emotional problems energy/fatigue, emotional wellbeing, social functioning, pain and general health pre and post treatment of the study group. 
Table (1): Basic characteristics of participants.

\begin{tabular}{|c|c|c|c|c|}
\hline & & & \multicolumn{2}{|c|}{ Study group } \\
\hline \multicolumn{3}{|c|}{$\begin{array}{l}\text { Age, mean } \pm(\mathrm{SD}), \text { years } \\
\text { BMI, mean } \pm(\mathrm{SD}), \mathrm{kg} / \mathrm{m}^{2} \\
\text { Duration of illness, mean } \pm(\mathrm{SD}), \text { month }\end{array}$} & \multicolumn{2}{|c|}{$\begin{array}{l}61 \pm 3.88 \\
25.58 \pm 2.13 \\
16.9 \pm 6.62\end{array}$} \\
\hline $\begin{array}{l}\text { Affected side, } n(\%) \text { : } \\
\text { Dominant side } \\
\text { Non dominant }\end{array}$ & side & & \multicolumn{2}{|c|}{$\begin{array}{l}5(50 \%) \\
5(50 \%)\end{array}$} \\
\hline \multicolumn{5}{|c|}{$\begin{array}{r}\text { Table (2): Median values of physical functioning, role limita- } \\
\text { tions due to physical health, role limitations due } \\
\text { to emotional problems energy/fatigue, emotional } \\
\text { wellbeing, social functioning, pain and general } \\
\text { health pre and post treatment of the study group. }\end{array}$} \\
\hline & $\begin{array}{l}\text { Pre treatment } \\
\text { Median (IQR) }\end{array}$ & $\begin{array}{l}\text { Post treatment } \\
\text { Median (IQR) }\end{array}$ & $\begin{array}{c}\mathrm{Z}- \\
\text { value }\end{array}$ & $\begin{array}{c}p- \\
\text { value }\end{array}$ \\
\hline $\begin{array}{l}\text { Physical } \\
\text { functioning }\end{array}$ & $40(51.25-20)$ & $\begin{array}{l}52.5 \\
(66.25-36.25)\end{array}$ & 2.53 & 0.01 \\
\hline $\begin{array}{l}\text { Role limitations } \\
\text { due to physical } \\
\text { health }\end{array}$ & $0(6.25-0)$ & $0(6.25-0)$ & 0 & 1 \\
\hline $\begin{array}{l}\text { Role limitations } \\
\text { due to emotional } \\
\text { problems }\end{array}$ & $0(0-0)$ & $0(0-0)$ & 0 & 1 \\
\hline Energy/fatigue & $35(45-33.75)$ & $45(51.25-35)$ & 2.55 & 0.01 \\
\hline $\begin{array}{l}\text { Emotional } \\
\text { well-being }\end{array}$ & $40(48-32)$ & $50(60-45)$ & 2.54 & 0.01 \\
\hline $\begin{array}{l}\text { Social } \\
\text { functioning }\end{array}$ & $43.75(53.12-25)$ & $50(75-50)$ & 2.42 & 0.01 \\
\hline Pain & $43.75(47.5-32.5)$ & $45(66-32.5)$ & 2.21 & 0.02 \\
\hline General health & $30(41.25 .-28.75)$ & $35(46.25-35)$ & 2.81 & 0.005 \\
\hline
\end{tabular}

IQR: Interquartile range. $\quad p$-value: Level of significance.

\section{Discussion}

The aim of this study was conducted to identify the effect of selected exercise program on quality of life in stroke patients. Ten male hemi-paretic patients following a stroke in the domain of the carotid artery participated in this study. The patients assigned into a selected group (GS). Therapeutic intervention the study was started at the same time for all patients of the study, the session time was 50-60min 3 times/week for eight weeks. Patients in the selected group (GS) received the traditional physical therapy program.

A detailed medical history was obtained in order to screen for other neurological diseases that affect quality of life besides stroke that may have an impact on the study. The American College of Sports Medicine (ACSM) criteria can be used to determine a patient's suitability to participate in training [9].

Results of this study showed a significant increase in physical functioning, energy/fatigue, emotional well-being, social functioning, pain and general health post treatment compared with that pre-treatment within group. Except for role limitation due to physicall health and role/limiation due to emotional problems where there was no significant difference. Within patients in this group pre and post treatment and they were the most affected domains in group.

Currently, there is a lack of evidence for treatment that is specifically designed to improve quality of life. The majority of chronic brain disorder treatments as stroke aim to alleviate disease-specific symptoms, progression, or relapse. In contrast, regardless of the type of disease, exercise therapy focuses on overall well-being, mood, and cognition [10].

We found a positive effect of exercise on quality of life, which was similar to the findings of other studies, including those investigating cancerl, [11,12], diabetes [13], cardiovascular disease [14] and the general population [15].

Other findings also supported the hypothesis that an eight week exercise programme improves overall QOL, physical functioning and psychological distress [16,17].

Finally, overall rehabilitation improves not only disability but also impairment. In terms of quality of life, as expected, there was a significant improvement in physical performance and ability in daily living activities in this sample. Surprisingly, there was a significant improvement in social function because previous studies at ward discharge found that social aspects of quality of life were significantly lower than physical aspects. The positive effect on social function could be attributed to progressive social integration in the rehabilitative structure over the course of the two-month treatment admission value [18]

\section{Conclusion:}

The results provide support for the use of exercise to improve quality of life in stroke survivors. and that eight weeks of training revealed significant difference. However, the present results emphasize that the selected physical therapy program can be used as an effectivee method for improving stroke patient's life quality. Also, Further research is recommended to investigate the impact of longer durations of such intervention or other effective strategies.

\section{References}

1- BENJAMIN E.J., VIRANI S.S., CALLAWAY C.W. CHAMBERLAIN A.M., CHANG A.R., CHENG S. and MUNTNER P.: Heart disease and stroke statistics-2018 update: A report from the American Heart Association. Circulation, 2018. 
2- AGUIAR L.T., NADEAU S., BRITTO R.R., TEIXEIRASALMELA L.F., MARTINS J.C. and de MORAIS FARIA C.D.C.: Effects of aerobic training on physical activity in people with stroke: Protocol for a randomized controlled trial. Trials, 19 (1): 1-8, 2018

3- SAUNDERS D.H., GREIG C.A. and MEAD G.E.: Physical activity and exercise after stroke: Review of multiple meaningful benefits. Stroke, 45 (12): 3742-3747, 2014.

4- WALSH M.E., GALVIN R., LOUGHNANE C., MACEY C. and HORGAN N.F.: Factors associated with community reintegration in the first year after stroke: A qualitative meta-synthesis. Disability and Rehabilitation, 37 (18): 1599-1608, 2015

5- PICKERING T.G., HALL J.E., APPEL L.J., FALKNER B.E., GRAVES J., HILL M.N. and ROCCELLA E.J.: Recommendations for blood pressure measurement in humans and experimental animals: Part 1: Blood pressure measurement in humans: A statement for professionals from the Subcommittee of Professional and Public Education of the American Heart Association Council on High Blood Pressure Research. Hypertension, 45 (1): 142-161, 2005.

6- JUBRAN A.: Pulse Oximetry: Review. Critical Care, 19: 272,2015

7- RIEBE D, et al.: eds. ACSM's Guidelines for Exercise Testing and Prescription. $10^{\text {th }}$ ed. Philadelphia, Pa. Wolters Kluwer Health Lippincott Williams \& Wilkins, 2018.

8- JACKSON A.S. (2007): Estimating maximum heart rate from age: Is it a linear relationship?. Medicine and science in sports and exercise, 39 (5): 821-821. Jubran A. Pulse oximetry. Crit Care, 19: 272, 2015.

9- THOMPSON W.R., GORDON N.F. and PESCATELLO L.S.: ACSM's guidelines for exercise testing and prescription. Wolters Kluwer Health/Lippincott Williams \& Wilkins, 2010.

10- DAUWAN M., BEGEMANN M.J., SLOT M.I., LEE E.H., SCHELTENS P. and SOMMER I.E.: Physical exercise improves quality of life, depressive symptoms, and cognition across chronic brain disorders: A transdiagnostic systematic review and meta-analysis of randomized controlled trials. Journal of Neurology, 1-25, 2019.

11- ADAMSEN L., QUIST M., MIDTGAARD J., ANDERSEN C., MØLLER T., KNUTSEN L. and RORTH M.: The effect of a multidimensional exercise intervention on physical capacity, well-being and quality of life in cancer patients undergoing chemotherapy. Supportive Care in Cancer, 14 (2): 116-127, 2006.

12- KENDALL A.R., MAHUE-GIANGRECO M., CARPENTER C.L., GANZ P.A. and BERNSTEIN L.: Influence of exercise activity on quality of life in long-term breast cancer survivors. Quality of Life Research, 14 (2): 361 $371,2005$.

13- CHYUN D.A., MELKUS G.D., KATTEN D.M., PRICE W.J., DAVEY J.A., GREY N. and WACKERS F.J.T.: The association of psychological factors, physical activity, neuropathy, and quality of life in type 2 diabetes. Biological research for Nursing, 7 (4): 279-288, 2006.

14- REJESKI W.J. and MIHALKO S.L.: Physical activity and quality of life in older adults. The Journals of Gerontology Series A: Biological Sciences and Medical Sciences, 56 (Suppl 2): 23-35, 2001.

15- HEESCH K.C., van UFFELEN J.G., van GELLECUM Y.R. and BROWN W.J.: Dose-response relationships between physical activity, walking and health-related quality of life in mid-age and older women. J. Epidemiol. Community Health, 66 (8): 670-677, 2012.

16- BURNHAM T.R. and WILCOX A.: Effects of exercise on physiological and psychological variables in cancer survivors. Medicine and science in sports and exercise, 34 (12): 1863-1867, 2002.

17- ML M., CAMPBELL K.L., ROWE B.H., KLASSEN T.P. MACKEY J.R. and COURNEYA K.S.: Effects of exercise on breast cancer patients and survivors: A systematic review and meta-analysis. CMAJ, 175: 34-41, 2006.

18- APRILE I., Di STASIO E., ROMITELLI F., LANCELLOTTI S., CALIANDRO P., TONALI P. and PADUA L.: Effects of rehabilitation on quality of life in patients with chronic stroke. Brain Injury, 22 (6): 451-456, 2008. 


\section{تأثير برنامج التمرين المختار على جودة الحياة

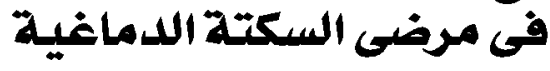

الخلفية: السكتة الدماغية هى أحد الأساليب الرئيسية للوفاة والعجز طويل الأمة فى جميع أنحاء العالم. الغرض: هدفت هذه الدراسة إلى إجراء تأثير برنامج تمارين مختارة على نوعية العياة فى مرضى السكتة الدماغية.

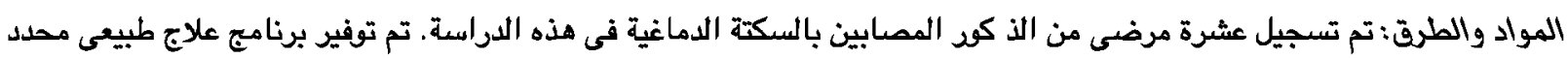

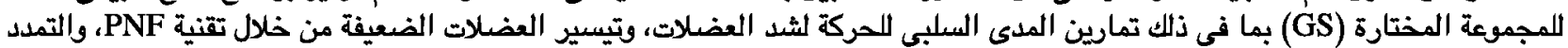

السريع.

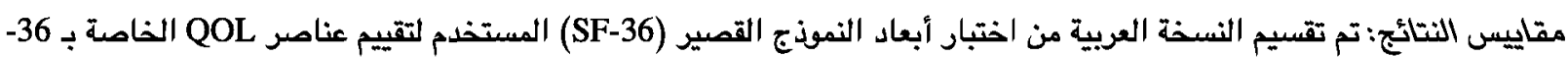

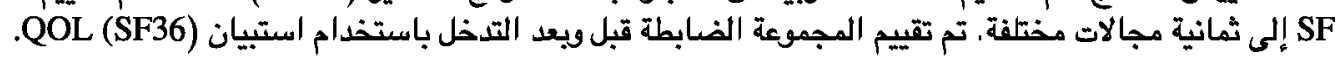

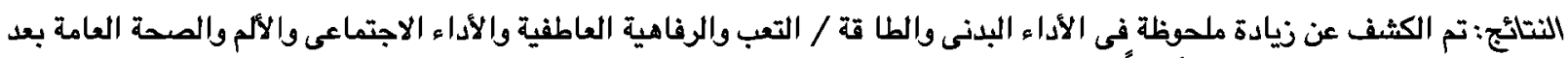

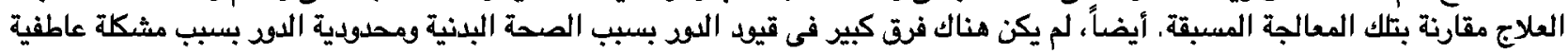
بين العلاج قبل ويعد العلاج في المجموعة المختارة.

الخلاصة: البر نامج الفيزيائى المختار يحسن بشكل ملحوظ نوعية العياة لدى مرضى السكتة الدماغية. 